\title{
Revisão Integrativa sobre a Vivência de Mães de Crianças com Transtorno de Espectro Autista
}

\author{
Integrative Review on the Living of Mothers of Children with Autistic Spectrum \\ Disorders
}
Revisión Integradora sobre la Vivencia de Madres de Niños con Trastorno del Espectro Autista

\author{
Alinne Souza Pinto \\ Teresinha Cid Constantinidis ${ }^{1}$ \\ Universidade Federal do Espírito Santo
}

\begin{abstract}
Resumo
Geralmente, é a mãe da criança com transtorno de espectro autista (TEA) que busca tratamento, dedica-se nos cuidados de seu filho, faz adaptações em seu cotidiano, podendo ter empobrecimento em sua vida social, afetiva e profissional, o que pode acarretar desgaste físico e emocional a essa mulher. O objetivo deste estudo foi identificar na literatura científica a sobrecarga das mães de crianças com TEA e as formas encontradas por elas para lidar com dificuldades cotidianas decorrentes dessa problemática. Foi realizada revisão integrativa da literatura dos últimos doze anos, em artigos científicos relacionados à temática citada. Do procedimento de busca, resultaram seis artigos para o banco final de análise. Os resultados apontam a sobrecarga emocional com o enfrentamento dessa fase, a perda do filho idealizado, confusão de sentimentos, medo, estresse, ter de lidar com o preconceito, assim como a necessidade dessa mãe em ter auxílio no cuidado com o filho.

Palavras-chave: transtorno autístico, relações mãe-filho, mães, estresse, sobrecarga emocional
\end{abstract}

\begin{abstract}
Generally, it is the mother of the child with autistic spectrum disorder (TEA) who dedicates herself to the care of her child, makes adaptations in her daily life, and may have impoverishment in her social, affective, and professional life, which can lead to physical and emotional exhaustion of this woman. This study aimed to identify in the scientific literature the overload of these mothers, as well as the coping strategies of the daily difficulties. An integrative review of the literature related to the subject, in the last twelve years, was carried out. The search procedure resulted in six articles for the final analysis bank. Because of this integral dedication, one can see the emotional overload with the confrontation of this phase, the loss of the child that was idealized, stress, dealing with prejudice, as well as the need of this mother to have assistance in caring for the child.
\end{abstract}

Keywords: autism, mother-child relations, mothers, stress, emotional overload

\section{Resumen}

En general, la madre del niño con trastorno del espectro autista (TEA) es quien busca tratamiento, se dedica al cuidado de su hijo, adapta su cotidiano, pudiendo tener empobrecimiento en su vida social, afectiva y profesional, lo que puede acarrear desgaste físico y emocional a esa mujer. El objetivo fue identificar en la literatura científica la sobrecarga de las madres de los niños con TEA, así como las formas encontradas por ellas para lidiar con las dificultades derivadas de esa problemática. Se realizó una revisión integradora de la literatura de los últimos doce años, en artículos relacionados con la temática citada. Del procedimiento de búsqueda, resultaron seis artículos para el banco final de análisis. Los resultados apuntan la sobrecarga emocional con enfrentamiento de esa fase, pérdida del hijo que fue idealizado, estrés, tener que lidiar con el prejuicio, así como la necesidad de esa madre en tener ayuda en el cuidado con el hijo.

Palabras clave: autismo, relaciones madre-niño, madres, estrés, sobrecarga emocional

\footnotetext{
${ }^{1}$ Endereço de contato: R. Moacir Avidos, 156, apt. 1102, Praia do Canto, Vitória, ES, CEP 29055-350. E-mail: teracidc@gmail.com
} 
O Manual de Diagnóstico e Estatística de Doenças Mentais (American Psychiatric Association, 2013), também referido como DSM-V, classifica o autismo, chamado de transtorno de espectro autista (TEA), como um transtorno global do neurodesenvolvimento, que se manifesta precocemente, sendo caracterizado por deficits que prejudicam o funcionamento pessoal, social, acadêmico ou profissional. Para critérios diagnósticos, os deficits devem ser persistentes na comunicação e interação social em diversos contextos, tendo padrões restritos e repetitivos de comportamento, de interesse ou de atividades, com sintomas presentes precocemente, e causarem prejuízo clínico significativo. Kupfer (2000) aponta que o conhecimento de um diagnóstico não garante o destino e o modo de vida de um indivíduo, pois cada diagnóstico carrega em si uma rede de significados socialmente definidos que podem aprisioná-lo dentro de determinados estereótipos e representações. A autora ressalta que essa rede de significados contribui para o processo de exclusão, marginalização e imobilismo perante a vida. O diagnóstico, no entanto, ocasiona importantes impactos no contexto familiar (Pinto et al., 2016). Diante do diagnóstico, algumas famílias podem se adaptar positivamente à realidade na adaptação com o filho com necessidade especial e outras podem vivenciar o processo de cuidado com profundo desgaste e desajuste familiar (Matsukura \& Sime, 2008).

Nesse processo de cuidado, a partir de uma implicação maior no tratamento, geralmente, na nossa cultura, são as mães que identificam algum problema, buscam o tratamento e acompanham seus filhos no cotidiano. Diante disso, tornam-se responsáveis pela administração das prescrições médicas e devem enfrentar e manejar as reações da criança em seu dia a dia. Embora não seja uma regra - principalmente com as mudanças de paradigmas de nossa época, podemos ver pais e outros familiares envolvidos no cuidado da criança com necessidades especiais -, ainda é possível observar a presença constante da mãe nas escolas e instituições que o filho frequenta. A mãe é o membro da família que mais faz adaptações em seus papéis e em suas rotinas de vida, diante do tempo de dedicação e cuidado com seu filho com necessidade especial (Matsukura, Marturano, Oishi, \& Borasche, 2007; Misquiatti, Brito, Ferreira, \& Assumpção, 2015). Independentemente da condição de saúde da criança, diante do papel de cuidadora, a rotina de cuidados diários, adaptações e mudanças gera nas mães grande cansaço físico e desgaste emocional, tornando essa população um grande alvo, com nível elevado de estresse (Cairo \& Sant'Anna, 2014).

Em face disso, essas mães têm de redimensionar as expectativas quanto ao futuro de seu filho com TEA e quanto ao próprio futuro, já que a demanda de cuidados pode gerar perdas e empobrecimento na vida social, afetiva e profissional dessas mulheres. Esse redimensionamento das atividades cotidianas por parte de familiares de pessoas com algum tipo de deficiência, o qual causa impactos econômicos, práticos e emocionais, é chamado de "sobrecarga familiar", do inglês family burden. Para Platt (1985, como citado em Campos \& Soares, 2005, p. 222), esse termo se refere à presença de problemas, a dificuldades ou eventos adversos que afetam significativamente a vida dos familiares e corresponde ao elemento de sofrimento explicitamente atribuído ao paciente.

Em relação ao impacto de ter um filho com necessidades especiais, essas mães têm seu cotidiano abalado pela sobrecarga de trabalho, reduzindo o tempo dedicado às atividades que gostam, vivenciam o preconceito, enfrentam burocracia para fazer uso de benefícios/ 
serviços disponíveis, além de terem de lidar com o comportamento da criança (Matsukura \& Sime, 2008). Schmidt e Bosa (2007) apontam que a indeterminação quanto ao futuro, especialmente em relação aos comportamentos de independência, às atividades da vida diária e à prática da vida social e escolar, suscita questionamentos de familiares dessas crianças a respeito dos cuidadores de seus filhos futuramente, quando eles não puderem provê-los.

É importante destacar que os estudos citados de sobrecarga familiar têm como objeto de análise familiares de pessoas com transtorno mental na fase adulta ou familiares de crianças com necessidades especiais, sem especificar a questão do autismo infantil (Campos \& Soares, 2005; Schmidt \& Bosa, 2007; Matsukura \& Sime, 2008). Schmidt, Dell'aglio e Bosa (2007) apontam a importância do apoio a essas mães para que elas possam lidar com os sentimentos decorrentes dessas vivências. Najarsmeha e Cezar (2011) ressaltam a importância de criar estratégias de intervenção que possibilitem a essas mulheres amenizar suas angústias e incertezas.

A fim de contribuir para o campo de pesquisa sobre as questões que envolvem o ser mãe de criança com TEA, especialmente como fonte de informação preliminar para o desenvolvimento de pesquisas nacionais na área, o presente estudo de revisão objetivou caracterizar as pesquisas realizadas no Brasil que contemplem a identificação da sobrecarga da mãe da criança com TEA, assim como as formas encontradas por essas mulheres para lidarem com as dificuldades cotidianas decorrentes dessa problemática.

\section{Método}

Trata-se de uma revisão integrativa de artigos científicos frutos de pesquisas realizadas sobre as vivências de mães de crianças com TEA. A revisão integrativa sumariza pesquisas e possibilita conclusões globais de um corpo de literatura de um tópico em particular, análise ampla da literatura, discussão de métodos e resultados, assim como reflexões sobre a realização de futuras pesquisas (Scorsolini-Comin \& Santos, 2010). Deste modo, visando responder aos objetivos da pesquisa, deu-se destaque para: a) vivência e/ou cotidiano das mães de crianças com TEA; b) Sobrecarga emocional, física, econômica, social e afetiva vivenciada por essas mães c) principais contribuições dos estudos e reflexões para futuras pesquisas.

\section{Estratégias de Buscas e Análise}

Estabeleceram-se os seguintes critérios de inclusão: a) ser um artigo científico fruto de pesquisa que responda ao objetivo geral da revisão; b) estar disponibilizado por completo na internet, indexado nas bases de dados Scientific Electronic Library Online (SciELO), Literatura Latino-Americana e do Caribe em Ciências da Saúde (LILACS) e no Portal de Periódicos Capes c) artigos científicos publicados nos últimos 12 anos (2007 a 2018) e revisado por pares. 
Figura 1

Estratégia de Busca e coleta de dados

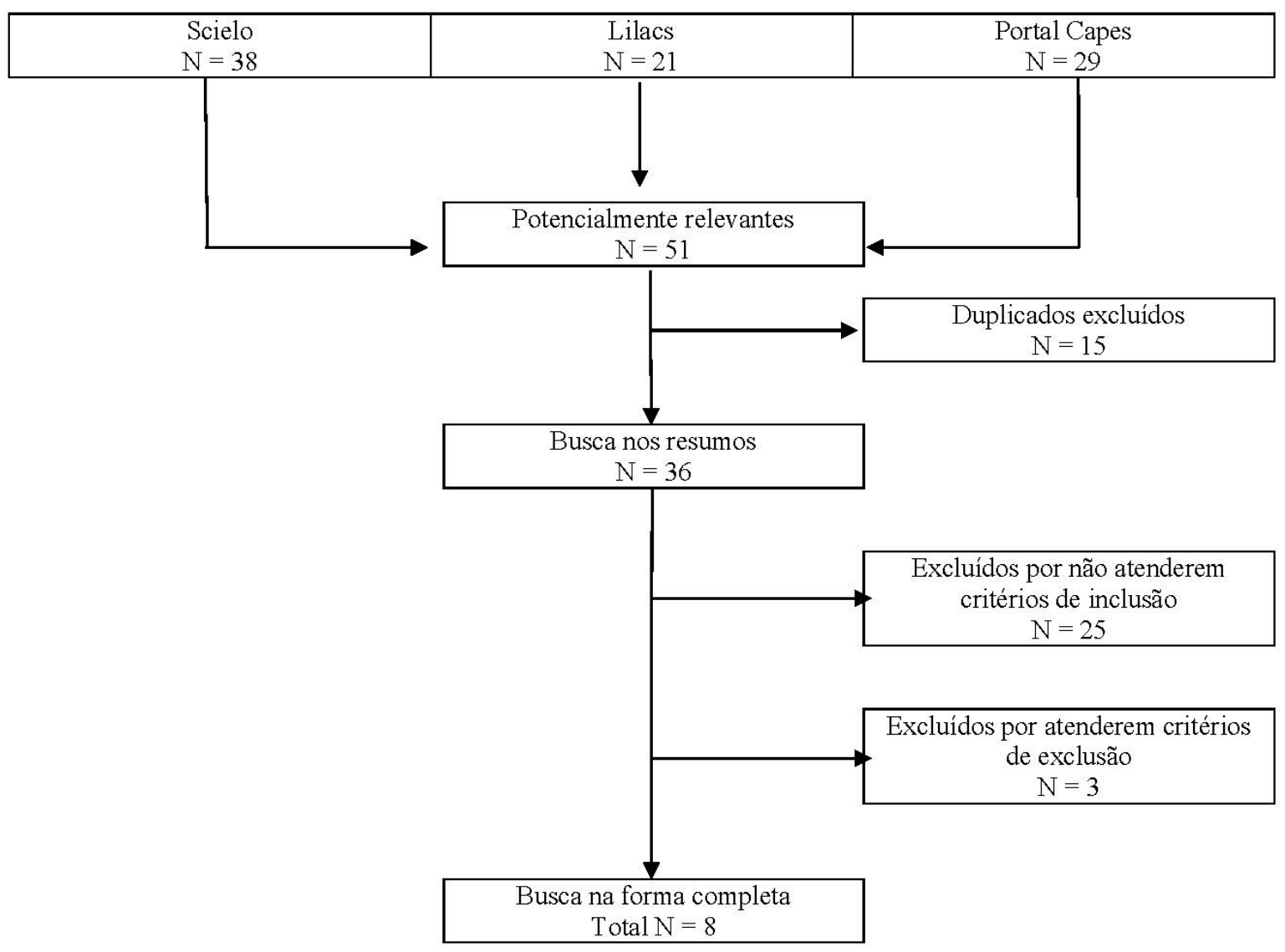

\section{Procedimentos de busca:}

- Os dados foram coletados utilizando-se busca nas bases de dados especificadas, no período descrito, em todos os campos, de acordo com os seguintes termos e seus sinônimos, no singular e plural, em português, no total ou em combinações possíveis dos termos, de acordo com o tema. Os termos utilizados foram: mães, autismo, cotidiano, encargos/sobrecarga, necessidades/demandas, atenção e cuidado/tratamento, saúde mental, qualidade de vida, estresse, transtorno autístico, maternidade.

- Foram excluídos estudos em formato de tese e dissertações, assim como livros e estudos referentes a outros temas de mães de crianças autistas, que não contemplam o objetivo da pesquisa. A seleção inicial resultou em dezesseis artigos. Dez artigos não atenderam um ou mais critérios de inclusão.

- Após o resultado inicial, foi feita a leitura dos resumos e a análise da amostra, de acordo com os critérios de inclusão e exclusão. A fim de assegurar os critérios de inclusão, em alguns casos, foi feita a leitura flutuante dos textos. Desse processo, restaram oito artigos para o banco final, conforme a Figura 1. 


\section{Resultados}

A Tabela 1 apresenta a síntese dos estudos levantados, destacando-se os objetivos, as técnicas de coleta de dados e as principais questões identificadas pelo estudo e que auxiliam na elucidação sobre a vivência dessas mães.

Tabela 1

Sintese dos artigos

Referências
Objetivos
Conhecer a vivência

de ser mãe de

criança autista

e compreender

o sentido dessa

vivência. filho autista: uma

compreensão pela

enfermagem. Rev.

Bras. Enferm., 61(3),

330-5.

Nunes, F. A. M.

\& Santos, A. M.

(2010). Depressão

e qualidade de vida

em mães de crianças

com Transtornos

Invasivos do

Desenvolvimento.

Rev. Latino-Am.

Enfermagem, 18(1).
Avaliar a prevalência de disforia/sintomas depressivos em mães de crianças com transtorno autístico e identificar possíveis relações com qualidade de vida e características sociodemográficas.
Estudo qualitativo, descritivo e analisado com o referencial da fenomenologia. Entrevista de perguntas abertas.

Método quantitativo, com utilização de Questionário do Perfil Sociodemográfico (QPS), Inventário Beck de Depressão (BDI), World Health Organization Quality of Life (WHOQOL-Bref).
Principais questões identificadas

O estudo concluiu que ser mãe de uma criança autista vai da superação ao privilégio, em que, ao mesmo tempo que essa criança é diferenciada, ela é especial. O cotidiano do filho é também vivido pela mãe. Em nenhum discurso as mães se lançam como ser de possibilidade, todas elas vivem exclusivamente para o lar, e o cuidar dedicado ao filho é incondicional. São mães que também precisam ser cuidadas, prevenindo o adoecimento psíquico e contribuindo para que elas possam cuidar do filho e se cuidarem.

As participantes com maior rendimento financeiro assinalaram significativamente apreciar melhor o domínio psicológico e ambiental da qualidade de vida. As mães com maior nível de escolaridade se mostraram menos vulneráveis aos critérios para disforia/ depressão e os escores foram maiores nos domínios psicológico, ambiental e físico. Os autores apontam a necessidade de investir na implementação de rede de suporte às famílias e ampliação de oportunidades de recreação e lazer para cuidadores de crianças com transtornos invasivos do desenvolvimento. 
Sanini, C., Brum,

M. H. E., \& Bosa,

A. C. (2010).

Depressão materna

e implicações sobre

o desenvolvimento

infantil do autista.

Rev. Bras. de

Crescimento e

Desenvolvimento

Humano, 20(3), 809-

815.

Najarsmeha, L., \&

Cezar, K. P. (2011).

A vivência da

maternidade de

mães de crianças

com autismo.

Psicologia em

Compreender

como as mães

de crianças com

autismo vivenciam a

maternidade.
Método

Principais questões identificadas

Os níveis de depressão são elevados entre mães de crianças com transtornos do desenvolvimento, como no caso do autismo. Medidas devem ser tomadas para auxiliar essas mães em uma situação que coloca em risco sua saúde mental e, assim, minimizar o impacto da depressão materna no desenvolvimento infantil. O estudo aponta a importância da presença do pai ou de outro adulto, não deprimido, bem como o uso de intervenções de suporte social. Pesquisas futuras devem verificar como o uso de uma rede de apoio social pelas mães resulta em comportamentos mais favoráveis tanto para ela quanto para o filho, assim como que tipo de apoio é mais eficaz no alívio dos sintomas depressivos.

Mães de crianças com autismo dedicam a vida aos cuidados com o filho, renunciam à carreira profissional, à vida social e às relações afetivas em prol dos cuidados maternos. Presentes nessas mães, estão sentimentos como incerteza, tristeza e desamparo.

As autoras ressaltam a necessidade de se possibilitar um espaço onde as mães possam ser escutadas, trocar experiências e amenizar suas angústias. 


Ebertb, M.,
Lorenzinic, E.,
\& Silva, F. E.
(2015). Mães
de crianças com
transtorno autístico:
percepções e
trajetórias. Rev.
Gaúcha de Enferm.,
36(1), 49-55.

Meimes, M. A., Saldanha, C. H., \& Bosa, A. C. (2015). Adaptação materna ao Transtorno do Espectro Autismo: Relações entre crenças, sentimentos e fatores psicossociais. Psico, 46(4), 412422.

\section{Conhecer as}

percepções de mães

de crianças com

autismo quanto

às alterações

apresentadas

pelo filho e às

suas trajetórias

percorridas na busca

pelo diagnóstico de autismo.
Investigar as crenças e os sentimentos maternos referentes ao diagnóstico, ao desenvolvimento infantil e às estratégias de manejo do comportamento da criança, relacionando-os aos fatores psicossociais presentes no contexto de vida das mães.

Método

Principais questões identificadas

Essas mães enfrentam dificuldades nas trajetórias percorridas em busca do diagnóstico do filho, peregrinam pelos serviços de saúde, passam por diversos profissionais e, em muitos casos, a confirmação diagnóstica ocorre Pesquisa qualitativa. tardiamente. É importante Entrevistas semiestruturadas.

Análise de conteúdo do tipo temática.

que os profissionais de saúde considerem as percepções maternas sobre o crescimento e desenvolvimento infantil, podendo favorecer para um diagnóstico precoce. $\mathrm{O}$ estudo revela a importância de o enfermeiro estar capacitado para o atendimento de crianças com autismo e seus familiares, durante a consulta de enfermagem e na educação permanente da equipe.

Foi possível observar tanto fatores psicossociais que facilitam quanto que dificultam a adaptação materna em contexto de TEA. Eles são relacionados às crenças e aos

Pesquisa qualitativa. Entrevista de Dados Demográficos e Desenvolvimento da Criança, Entrevista de Percepção Materna, Questionário de Saúde Geral de Goldberg (QSG). Análise de conteúdo proposto por Bardin (1999) e complementado por Laville e Dionne (1999). sentimentos investigados, um deles sendo o sentimento de culpa quanto ao diagnóstico do filho, e refletem as crenças sobre o TEA. Outros sentimentos presentes são: tristeza, estresse, injustiça, esperança, desejo, insegurança, frustração, decepção, entre outros. A falta de compreensão da criança é geradora de intensa frustração e sofrimento materno. Alguns fatores psicossociais podem influenciar negativamente a adaptação materna em contexto de TEA, sendo eles a falta de apoio social e conjugal, pouco acesso aos serviços de saúde, sobrecarga materna e os desafios impostos pela doença. 
Principais questões identificadas
Constantinidis, $\mathrm{T}$.

C. C., Silva, L. C., \& Ribeiro, M. C. C. (2018). Todo mundo quer ter um filho perfeito: Vivências de mães de crianças com autismo. PsicoUSF, 23(1), 47-58.

Ferreira, M., \&

Smeha, L. N. (2018).

A experiência de ser mãe de um filho com autismo no contexto da monoparentalidade. Psicologia em Revista, 24(2), 462481.
Compreender a vivência de mães de crianças com autismo e discutir diferentes aspectos dessas experiências com base nos discursos dessas mães e na literatura sobre o tema.

\section{Conhecer a} experiência de ser mãe de um filho com autismo no contexto da monoparentalidade.
Pesquisa qualitativa. Entrevista semiestruturada. Análise de conteúdo (Bardin, 1999).

Os resultados configuraram três temas: impacto do diagnóstico de autismo, suporte social e ser mulher e mãe de criança com autismo. Esses temas corroboram dados da literatura quanto ao impacto do autismo no cotidiano dessas mulheres, aos encargos enfrentados por elas e à importância da rede social de apoio. Destacam-se como achados deste estudo a importância do diagnóstico como norteador das ações dessas mães e a resistência dos profissionais em fornecêlo, além do pai da criança com dificuldades em aceitar a condição do filho, mas resgatando a identidade feminina dessa mãe.

Os resultados revelaram que os sentimentos e desafios são semelhantes aos de mães de filhos com autismo que não vivem no contexto monoparental. Acreditase que a diferença possa estar na intensidade; isto é, na monoparentalidade, as dificuldades podem ser agravadas pela ausência de um companheiro. Sobre a possibilidade de um novo relacionamento afetivo, quando há, mesmo que remota, não está centrada na necessidade de auxílio nos cuidados com o filho, mas no apoio emocional. Entre os fatores que contribuem para a manutenção da monoparentalidade, destacam-se a priorização do papel materno, a adolescência do filho, além de uma rede de apoio restrita. 
Os artigos de Sanini, Brum e Bosa (2010) e Nunes e Santos (2010) não contemplam aspectos vivenciais das mães de crianças com TEA em seus objetivos e abordam aspectos específicos da depressão dessas mães. No entanto o desenvolvimento desses estudos traz contribuições importantes sobre a vivência dessas mães que vão ao encontro dos objetivos desta revisão.

Os estudos apresentados usam metodologia variada, mas predominantemente de cunho qualitativo, com entrevistas às mães de crianças com TEA. A exceção se faz por estudo de revisão integrativa de literatura e outro que se caracteriza por metodologia mista, qualitativa e quantitativa.

\section{Discussão}

Os resultados apontam que as mães das crianças com TEA percebem diferenças em seus filhos em relação às crianças com desenvolvimento típico e, a partir de suas percepções, buscam atendimento de saúde e iniciam a trajetória na busca por respostas às alterações percebidas, geralmente, na atenção primária. Nem sempre recebem respostas que elucidem o diagnóstico e passam a enfrentar uma peregrinação pelos serviços e profissionais de saúde em busca de respostas para alterações apresentadas no modo de ser do filho (Ebertb, Lorenzinic, \& Silva, 2015; Constantinidis, Silva, \& Ribeiro, 2018). Estudo de Sanini et al. (2010) aponta que o impacto do diagnóstico nessas mães é intenso e marcado por dúvidas, incertezas e tristezas, as quais se intensificam em decorrência de uma rede de apoio restrita.

Segundo Constantinidis et al. (2018), a necessidade do familiar de compreender essa vivência com o filho, a observação do comportamento diferente, vem formulada pelo pedido de um diagnóstico. O diagnóstico parece ser um norteador para o familiar, que, até então, pode sentir-se à deriva com suas experiências e alienado quanto às suas ações. O diagnóstico psicopatológico é um lugar que as vivências dos familiares passam a ocupar, podendo ser referido com um nome. Deixa a categoria de inominável para a concretude de um código a ser compartilhado, dando garantia de doença àquilo que vivenciam na relação com a criança. Assim, o diagnóstico não é só necessidade de profissionais, que muitas vezes se furtam da tarefa de conversar sobre o tema com a família, mas também dos familiares.

Em relação a essa necessidade de familiares em entender o comportamento diferente da criança, Ebertb et al. (2015) ressaltam a importância do preparo de profissionais da educação infantil para detectar sinais e sintomas do autismo infantil, a fim de que possam auxiliar as mães e famílias e encaminhar as crianças a outros profissionais para avaliação diagnóstica. Os autores destacam também a importância de os profissionais de saúde considerarem as percepções maternas sobre o crescimento e desenvolvimento infantil, podendo favorecer para um diagnóstico precoce.

Enfrentar essa nova e inesperada realidade causa sofrimento, confusão, frustrações e medo a essas mães (Najarsmeha, \& Cezar, 2011), que podem ser bastante atingidas emocionalmente, pois se deparam com a perda do filho imaginado por elas e, por isso, correm o risco de apresentar sentimentos como tristeza, frustração, ambivalência e negação, os quais podem alterar o relacionamento mãe-criança (Sanini et al., 2010). Franco (2015) analisa a relação da mãe com o bebê imaginado sob três perspectivas. Em primeiro lugar, estaria uma componente estética: o bebê ideal tem características de perfeição física e estética, 
incorporando semelhanças com os pais. Em segundo, estaria uma dimensão de competência em que o bebê é esperado como intelectualmente competente, com capacidades que correspondam ao estilo de vida e aos valores dos pais. Em terceiro, estaria a perspectiva de futuro para essa criança, e os pais imaginam um futuro ideal para ela, que um dia cursará os seus estudos, será um profissional de sucesso e realizado. Para o autor, essas dimensões imaginárias e idealizadas são fundamentais para que os pais possam enfrentar as exigências colocadas pelo cuidar de um bebê. No entanto, diante de um filho com deficiência:

Dizem alguns que, perante isto, é inevitável a depressividade crônica, o luto crônico, ferida narcísica insuperável reaberta pela presença constante da criança... Um vasto conjunto de comportamentos tem a ver com a expressão emocional do sofrimento que a situação trouxe. Muitos destes movimentos estão interligados ou mascarados, como, por exemplo, a revolta, raiva, negação, culpabilização ou os sentimentos depressivos. (Franco, 2015, pp. 209-210)

Meimes, Saldanha e Bosa (2015) destacam que o sentimento de culpa quanto ao diagnóstico do filho é um dos fatores que mais dificultam a adaptação da mãe dessa criança a essa nova situação. Monteiro et al. (2008) apontam que a mãe da criança com TEA se dedica ao filho de tal forma que passa a relatar o cotidiano do filho como seu próprio cotidiano e, na intensa dedicação e prestação desses cuidados, Najarsmeha e Cezar (2011) afirmam que são as mães que mais sofrem ajustes de planos e expectativas em sua vida pessoal e apresentam maior incidência de estresse e depressão.

A autorresponsabilização recai também sob a crença de que a sintomatologia do filho é explicada pelo seu mau desempenho como mãe. Isso permite que essa mãe atribua a si todo e qualquer compromisso com o filho, inclusive o manejo com o resto da família (Sanini et al., 2010). Muitas dessas mães dedicam integralmente seu dia ao filho e, em prol dos cuidados com essa criança, não podem trabalhar fora ou exercer outra atividade, abdicando da carreira profissional, além da vida social e das relações afetivas (Monteiro et al., 2008; Nunes \& Santos, 2010; Najarsmeha \& Cezar, 2011, Constantinidis et al., 2018). Esse resultado confirma o estudo de Matsukura et al. (2007), que cita que é a mãe quem mais faz adaptações em sua rotina para dedicar seu tempo e cuidados à criança autista. A mãe toma para si a maior carga de responsabilidade no cuidado do filho. Em relação à imagem da mulher, esta é identificada, de forma acrítica, ao afeto, à maternidade e ao amor incondicional (Gutierrez \& Minayo, 2009).

Milbrath, Cecagno, Soares, Amestoy e Siqueira (2008) apontam que, ao adotar essa atitude de se dedicar integralmente ao filho, abdicando de sua vida social, profissional e pessoal, visto que a priorização é dada ao papel de ser mãe, essa mãe pode estar, inconscientemente, exigindo de si mesma a obrigação e a responsabilidade de cuidar daquele que ela foi capaz de gerar. Assim, essa mãe considera o fato de cuidar do filho como uma necessidade intrinsecamente determinada. Segundo os autores, esse processo vivenciado pela mãe, associado à vocação feminina para o cuidado, provavelmente pode ser considerado o responsável pelo fato de a mãe ser a principal cuidadora.

No cuidado com o filho com TEA, as mães agem de forma objetiva e prática para resolver os problemas e demonstram manejo adequado diante das dificuldades, das circunstâncias estressoras surgidas no cotidiano, incluindo o convívio familiar e social mais amplo (Meimes 
et al., 2015). No entanto Sanini et al. (2010) ressaltam que o cotidiano com o filho com autismo não deixa de ser estressante, na medida em que existe uma sobrecarga adicional em todos os níveis: social, psicológico, financeiro e, também, nos cuidados com a criança. Os resultados desse último estudo corroboram os resultados de estudo de Piovesan, Scortegagna e Marchi (2015), que apontam que o tratamento de rotina fornecida para as crianças, muitas vezes, leva as mães a negligenciar o seu próprio cuidado, prejudicando o seu bem-estar. Ferreira e Smeha (2018) destacam que as dificuldades para essas mães podem ser agravadas pela ausência de um companheiro.

Sanini et al. (2010) apontam que, para muitas mães, a realização de atividades de lazer é difícil devido à falta de tempo, dada a necessidade de cuidados continuados e permanentes de sua criança. Essas mães procuram desenvolver atividades alternativas, como ler, conversar, ver televisão, para, assim, poder desligar-se do foco estressor. Este tipo de estratégia é semelhante à estratégia de evitação, que também foi apresentada pelas mães nessas situações, quando elas procuram evitar pensar sobre o problema (Schmidt et al., 2007). No entanto, muitas vezes, essas mães se afastam de atividades de lazer e do convívio social por causa do preconceito e dos comportamentos agressivos do filho (Sanini et al., 2010; Constantinidis et al., 2018). Segundo Rendón (2016), o comprometimento do desenvolvimento cognitivo social e comportamental da criança com TEA interfere diretamente no convívio e no estabelecimento de relações sociais com outras pessoas, dificultando sua adaptação no meio em que vive e trazendo o preconceito e estigma social. O estudo dessa autora aponta que os familiares sofrem com o preconceito e com o comportamento imprevisível de seus filhos, tornando a vida cotidiana um desafio e muitas vezes solitária.

As dificuldades enfrentadas por essas mães se devem, sobretudo, à insegurança em lidar com as demandas do filho de forma satisfatória, à dificuldade de aceitação do diagnóstico, à falta de apoio social e conjugal percebida e à possível restrita rede de saúde (Najarsmeha \& Cezar, 2011). Bradford (1997) aponta, em relação aos familiares de crianças com alguma condição crônica, a interdependência de vários fatores que podem levar ao agravamento da condição da família e da criança. Esse autor relata que a falta de apoio conjugal pode contribuir para o incremento dos sentimentos de solidão e desamparo maternos. Para o autor, quando não há colaboração entre os pais no cuidado com a criança, os níveis de estresse parental tendem a aumentar e ocasionar uma consequente exacerbação dos sintomas da criança, dificultando a adaptação. No entanto o estudo de Ferreira e Smeha (2018) destaca que, na monoparentalidade de mães de crianças com autismo, a possibilidade de um novo relacionamento afetivo não está centrada na necessidade de auxílio nos cuidados com o filho, mas no apoio emocional.

O apoio social foi referenciado como um mediador e moderador do otimismo e do bem-estar materno. Os resultados de pesquisa de Meimes, Saldanha e Bosa (2015) revelaram que o apoio do cônjuge, de familiares e de amigos foi associado ao crescimento do otimismo e a maiores níveis de respostas maternas positivas em relação à criança. Assim, as mães precisam contar com o auxílio de outras pessoas ou instituições para conseguirem dar conta da sobrecarga de cuidados com a criança autista. O estudo de Najarsmeha e Cezar (2011) aponta impactos de apoio religioso, pois, segundo os resultados do referido estudo, a religião traz conforto a angústias dessas mães, facilitando a adaptação a essa situação adversa. 
Portanto as redes de apoio/suporte social, entre elas a religiosidade, atuam como auxílio a essas mulheres, ajudando-as a melhor viver a maternidade.

São as mães que também precisam ser cuidadas, prevenindo o adoecimento psíquico e contribuindo para que elas possam cuidar do filho e se cuidarem (Monteiro et al., 2008). É importante destacar que os níveis de depressão são elevados entre mães de crianças com TEA, conforme mostra o estudo de Sanini et al. (2010). Esse mesmo estudo aponta medidas que devem ser tomadas para auxiliar essas mães em uma situação que coloca em risco sua saúde mental e, assim, minimizar o impacto da depressão materna no desenvolvimento infantil. Ainda nessa seara, o estudo de Nunes e Santos (2010) aponta que as mães com maior nível socioeconômico e de escolaridade se mostraram significativamente menos vulneráveis aos critérios para disforia/depressão e apresentaram maiores escores nos domínios psicológico, ambiental e físico. Esses dados apontam que o baixo nível de renda familiar e a avaliação menor do domínio ambiental, diante dos demais aspectos da qualidade de vida, denotam escassez de recursos financeiros. Mães com possibilidades financeiras poderiam viabilizar o pagamento de um cuidador para a criança, permitindo dedicarem-se à profissão ou ao trabalho, ou mesmo usufruírem de lazer, relaxamento, pois se observou limitação importante na capacidade de desfrutar prazer na vida ou alcançar satisfação.

O acesso a lazer, saúde, transporte e serviços desempenha um papel importante na percepção de qualidade de vida das mães, sendo importante a implementação de políticas e estratégias que forneçam esse tipo de acesso, além da importância de um olhar cuidadoso sobre a depressão materna. Sanini et al (2010) ressaltam a importância de ampliar as oportunidades de recreação e lazer para os cuidadores de crianças com transtornos invasivos do desenvolvimento. Além disso, estratégias de intervenção são necessárias para possibilitar a essas mulheres um espaço no qual elas possam ser escutadas, trocar experiências, compartilhar sua dor e sofrimento e amenizar suas angústias e incertezas (Najarsmeha \& Cezar, 2011).

Nunes e Santos (2010) e Sanini et al. (2010) ressaltam a necessidade de investir na implementação de uma rede de suporte às famílias. Nesse sentido, Minatel e Matsukura (2014) apontam que a rede de suporte, atenção e políticas direcionadas às crianças com TEA e suas famílias interfere diretamente no enfrentamento das dificuldades advindas da atenção e cuidado a essas crianças. As autoras citam a Lei n. 12.764/2012, a qual institui a Política Nacional de Proteção aos Direitos da Pessoa com Transtorno do Espectro Autista como marco legal, que garante a essas crianças o direito à educação, bem como a tratamentos adequados e especializados. Também destacam a ação desenvolvida pelo Ministério da Saúde (Brasil, 2015), com a divulgação do documento "Linha de cuidado para a atenção integral às pessoas com transtorno do espectro do autismo e suas famílias no Sistema Único de Saúde (SUS)", que direciona as ações junto a essa população no âmbito do SUS, articulado pela Rede de Atenção Psicossocial (RAPS). A RAPS, nesse sentido, por seu caráter integrado e intersetorial nos diferentes equipamentos de saúde, da assistência social, jurídico e educacional, traz o caráter interdisciplinar necessário para responder à complexidade da realidade vivida pelas pessoas com autismo e suas famílias. 


\section{Considerações Finais}

Esta proposta de pesquisa se torna importante para o conhecimento que vem sendo produzido na área, para reflexão sobre esse conhecimento e para proposição de práticas de intervenção com essa população. Segundo os resultados obtidos, podemos concluir que, no cotidiano dessas mães, o cuidado com as crianças com TEA vem como prioridade. Elas dedicam-se integralmente a esses cuidados, percorrendo longas trajetórias atrás de diagnósticos e tratamentos, peregrinando pelos serviços de saúde, resultando em escassez de tempo para atividades de autocuidado, profissionais, sociais e de lazer. Como consequência dessa dedicação integral, os estudos apontam a sobrecarga emocional com o enfretamento dessa fase.

Como necessidades e demandas, os estudos apontam a importância de poder dividir esse cuidado com outra(s) pessoa(s) ou ter auxílio institucional, em que a atenção esteja voltada para além da criança com autismo, mas também para o cuidado dessa mãe. Além disso, como modo de atenção e cuidado, os resultados apontam a importância das redes de apoio e suporte, com trocas com outras mães que passam pela mesma situação.

Destacamos a dificuldade em separar o cotidiano dessas mães da sobrecarga que elas têm como a principal adversidade encontrada no estudo. Por diversas vezes, esses dois tópicos se misturavam e pareciam estar interligados, indicando que a sobrecarga faz parte desse cotidiano de forma óbvia e clara.

Como limitação deste estudo, apontamos a busca de artigos nacionais como estratégia de pesquisa, impedindo a ampliação de busca em outras línguas e a ampliação para um panorama internacional da produção científica sobre o tema. No entanto destaca-se que a busca realizada trouxe a realidade brasileira, e estudos posteriores em outras línguas possibilitarão comparações com a nossa realidade.

\section{Referências}

American Psychiatric Association. (2013). Diagnostic and statistical manual of mental disorders (5th ed.). Arlington, VA: American Psychiatric Publishing.

Bradford, R. (1997). Children, families and chronic disease. Londres: Routledge.

Brasil. (2015). Ministério da Saúde. Secretaria de Atenção à Saúde. Departamento de Ações Programáticas Estratégicas. Linha de cuidado para a atenção às pessoas com transtornos do espectro do autismo e suas famílias na Rede de Atenção Psicossocial do Sistema Único de Saúde. Brasília: Ministério da Saúde.

Campos, H. P. F., \& Soares, C. B. (2005). Representação da sobrecarga familiar e adesão aos serviços alternativos em saúde mental. Psicologia em Revista, 11(18), 219-237. Disponível em http://periodicos.pucminas.br/index.php/psicologiaemrevista/article/view/233/243

Cairo, S., \& Sant'Anna, C. C. (2014). Estresse em mães e cuidadoras de crianças e adolescentes com asma: um estudo sobre a frequência do estresse e fatores estressores. Cadernos Saúde Coletiva, 22(4), 393-400. doi: https://dx.doi.org/10.1590/1414-462X201400040013

Constantinidis, T. C., Silva, L. C., \& Ribeiro, M. C. C. (2018). "Todo mundo quer ter um filho perfeito": Vivências de mães de crianças com autismo. Psico-USF, 23(1), 47-58. doi: https://dx.doi.org/10.1590/1413-82712018230105

Ebertb, M., Lorenzinic, E., \& Silva, F. E. (2015). Mães de crianças com transtorno autístico: Percepções e trajetórias. Revista Gaúcha de Enfermagem, 36(1), 49-55. 
Ferreira, M., \& Smeha, L. N. (2018). A experiência de ser mãe de um filho com autismo no contexto da monoparentalidade. Psicologia em Revista, 24(2), 462-481.

Franco, V. (2015) Paixão-dor-paixão: Pathos, luto e melancolia no nascimento da criança com deficiência. Revista Latinoamericana de Psicopatologia Fundamental, 18(2), 204-220. doi: https://dx.doi.org/10.1590/1415-4714.2015v18n2p204.2

Gutierrez, D. M. D., \& Minayo, M. C. S. (2009). Papel da mulher de camadas populares de Manaus na produção de cuidados da saúde. Saúde e Sociedade, 18(4), 707-20. Disponível em https://www.revistas.usp.br/sausoc/article/download/29496/31356

Kupfer, M. (2000). Notas sobre o diagnóstico diferencial da psicose e do autismo na infância. PsicologiaUSP,11(1), 85-105. doi:https://dx.doi.org/10.1590/S0103-65642000000100006

Lei n. 12.764, de 27 de dezembro de 2012. (2012). Institui a Política Nacional de Proteção dos Direitos da Pessoa com Transtorno do Espectro Autista; e altera o § 30 do art. 98 da Lei n. 8.112, de 11 de dezembro de 1990. Diário Oficial [da] República Federativa do Brasil, Brasília, DF.

Matsukura, T. S., Marturano, E. M., Oishi, J., \& Borasche, B. (2007) Estresse e suporte social em mães de crianças com necessidades especiais. Revista Brasileira de Educação Especial, 13 (3), 415-28. doi: https://dx.doi.org/10.1590/\$1413-65382007000300008

Matsukura, T., \& Sime, M. (2008), Demandas e expectativas de famílias de crianças com necessidades especiais: de situações do cotidiano aos técnicos envolvidos no tratamento. Temas sobre Desenvolvimento, 16(94):214-220

Meimes, M. A., Saldanha, C. H., \& Bosa, A. C. (2015). Adaptação materna ao transtorno do espectro autismo: Relações entre crenças, sentimentos e fatores psicossociais. Psico, 46(4), 412-422.

Milbrath, V. M., Cecagno, D., Soares, D. C., Amestoy, S. C., \& Siqueira, H. C. H. (2008). Ser mulher mãe de uma criança portadora de paralisia cerebral. Acta Paulista de Enfermagem, 21(3), 427-431. doi: https://dx.doi.org/10.1590/S0103-21002008000300007

Minatel, M. M., \& Matsukura. T. S. (2014). Famílias de crianças e adolescentes com autismo: Cotidiano e realidade de cuidados em diferentes etapas do desenvolvimento. Revista de Terapia Ocupacional da Universidade de São Paulo, 25(2), 126-134. doi: https://doi. org/10.11606/issn.2238-6149.v25i2p126-134

Misquiatti, A. R. N., Brito, M. C., Ferreira, F. T, S., \& Assumpção, F. B. Junior. (2015). Sobrecarga familiar e crianças com transtornos do espectro do autismo: Perspectiva dos cuidadores. Revista CEFAC: Atualização Científica em Fonoaudiologia e Educação, 17(1), 192-199. doi: https://dx.doi.org/10.1590/1982-0216201520413

Monteiro, S. F. C., Batista, M. N. O. D., Moraes, C. C. E., Magalhaes, S. T., Nunes, T. V. M. B., \& Moura, B. E. M. (2008). Vivências maternas na realidade de ter um filho autista: Uma compreensão pela enfermagem. Revista Brasileira de Enfermagem, 61(3), 330-335.

Najarsmeha, L., \& Cezar, K. P. (2011). A vivência da maternidade de mães de crianças com autismo. Psicologia em Estudo, 16(1), 43-50. doi: https://doi.org/10.1590/ S1413-73722011000100006

Nunes, F. A. M., \& Santos, A. M. (2010). Depressão e qualidade de vida em mães de crianças com Transtornos Invasivos do Desenvolvimento. Revista Latino-Americana de Enfermagem, 18(1), 1-9. 
Pinto, R. N. M., Torquato, I. M. B., Collet, N., Reichert, A. P. S., Souza Neto, V. L., \& Saraiva, A. M. (2016). Autismo infantil: Impacto do diagnóstico e repercussões nas relações familiares. Revista Gaúcha de Enfermagem, 37(3), e61572. https://dx.doi. org/10.1590/1983-1447.2016.03.61572

Piovesan, J., Scortegagna, A. S., \& Marchi, B. A. (2015). Qualidade de vida e sintomatologia depressiva em mães de indivíduos com autismo. Psico-USF, 20(3), 505-515. doi: https:// doi.org/10.1590/1413-82712015200312

Rendón, D. C. S. (2016). Vivências de mães de crianças com transtorno de espectro autista: Implicações para a enfermagem (Dissertação de Mestrado em Enfermagem, Universidade Federal de Juiz de Fora, Minas Gerais). Disponível em https://repositorio.ufjf.br/jspui/ handle/ufff/4052

Sanini, C., Brum, M. H. E, \& Bosa, A, C. (2010) Depressão materna e implicações sobre o desenvolvimento infantil do autista. Rev. Bras. de Crescimento e Desenvolvimento Humano, 20(3), 809-815.

Schmidt, C., \& Bosa, C. (2007) Estresse e auto-eficácia em mães de pessoas com autismo. Arquivos Brasileiros de Psicologia, 59(2), 179-191. Disponível em http://pepsic.bvsalud. org/scielo.php?script=sci_arttext\&pid=\$1809-52672007000200008\&lng=pt\&nrm=iso

Schmidt, C., Dell'aglio, D., \& Bosa, C. A. (2007). Estratégias de copping de mães de portadores de autismo: Lidando com dificuldades e com a emoção. Psicologia: Reflexão e Crítica, 20 (1), 124-131. doi: https://doi.org/10.1590/S0102-79722007000100016

Scorsolini-Comin, F., \& Santos, M. (2010). Satisfação conjugal: Revisão integrativa da literatura científica nacional. Psicologia: Teoria e Pesquisa, 26(3), 525-532. doi: https:// dx.doi.org/10.1590/S0102-37722010000300015

Recebido em: 21/08/2018

Última Revisão: 21/05/2019

Aceite Final: $31 / 05 / 2019$

\section{Sobre as autoras:}

Alinne Souza Pinto: Terapeuta Ocupacional pela Universidade Federal do Espírito Santo. Terapeuta ocupacional do Centro de Referência de Assistência Social (CREAS-Centro), Vitória, ES. E-mail: linnee_souza@hotmail.com, Orcid: https://orcid.org/0000-0001-7868-9539

Teresinha Cid Constantinidis: Doutora em Psicologia pela Universidade Federal do Espírito Santo (UFES). Mestre em Psicologia Social pela Universidade de São Paulo (USP). Professora adjunta IV do Departamento de Terapia Ocupacional e professora do Programa de Pós-Graduação em Psicologia da UFES. E-mail: teracidc@gmail.com, Orcid: http://orcid.org/0000-0001-9712-3362 
